Research Article

\title{
Drug utilization study of antiepileptic drugs in tertiary care hospital
}

\author{
Asha Sureshrao Morge ${ }^{1 *}$, Madhuri Kulkarni
}

${ }^{1}$ Department of Pharmacology, Dr. S. C. G. M. C. Nanded, Maharashtra, India ${ }^{2}$ Department of Pharmacology, Govt. Medical College Aurangabad, Maharashtra, India

Received: 05 August 2016 Accepted: 06 September 2016

*Correspondence to:

Dr. Asha Sureshrao Morge, Email: ashamorge@gmail.com

Copyright: (C) the author(s), publisher and licensee Medip Academy. This is an openaccess article distributed under the terms of the Creative Commons Attribution NonCommercial License, which permits unrestricted noncommercial use, distribution, and reproduction in any medium, provided the original work is properly cited.

\begin{abstract}
Background: Study of the epidemiology of epilepsy and is of immense value in understanding the causes, outcome and prevention of epilepsy. It is also useful in planning proper services for persons with epilepsy and improving their quality of life. There is an urgent need for studies regarding incidence of epilepsy, prevalence of epilepsy syndromes, risk factors, and pharmacotherapy data from developing countries such as India.

Methods: A prospective observational study. All ages, either gender receiving Antiepileptic prescription in epilepsy OPD. 6 months study duration.

Results: Prescription of 562 patients was studied. The demographic data revealed that number of male and female patients were $53 \%$ and $47 \%$ respectively. Generalized tonic-clonic seizures accounted for almost $62 \%$, followed by partial seizures, myoclonic seizures and others (traumatic, infectious, systemic disorder, metabolic derangement). Monotherapy was used in majority of patients.

Conclusions: Drug utilization studies have always helped in modifying the prescription guidelines according to the pattern of diseases coming to the healthcare centres. These kinds of studies have an important role in studying and making rational prescription and making drug utilization at most useful to the patients.
\end{abstract}

Keywords: DUS, Epilepsy, Antiepileptic drugs

\section{INTRODUCTION}

The beginning of drug utilization studies can be traced back to the early 1960s. During a symposium on drug toxicology organized by the WHO in Moscow in 1964, serious consideration was first given to major public studies of drug utilization. Similar too many other developments at the time, drug utilization had been sparked off by the thalidomide disaster People came to the realization that if they had no idea of the scale on which (and the manner in which) such dangerous products had been employed; they were not in a position to assess the frequency and location of the risks. The Moscow meeting led to a study of drug consumption in six European countries in the 1966 to 1967 period, which showed great differences in drug use. This study was followed by a symposium entitled, "The consumption of drugs" in Oslo in 1969, which clearly confirmed that an internationally accepted classification system was needed for presenting data on drug consumption. Drug utilization studies were originally a northern European project but have since spread to all the parts of the world. It was initially motivated by economic considerations but has become one serving the interests of efficient, effective and safe medicine. ${ }^{1}$

Drug use/usage/utilization evaluation (DUE) was originally known as drug utilization review (DUR) in the 1970's and early 1980's.The terms drug utilization review (DUR) and drug use evaluation (DUE) is interchangeable. $^{2}$

Drug utilization was defined by World Health Organization (WHO) in 1977 as "the marketing, 
distribution, prescription, and use of drugs in a society, with special emphasis on the resulting medical, social and economic consequences.",

There are about 20 epidemiological studies on epilepsy from different parts of India. They include both rural and urban studies. The prevalence rate stands at around $5 / 1000$ population (at this rate present estimate of total epileptics in this country is about 5 million) and incidence rate varies from 38 to 49.3 per 100,000 population per year from two community-based studies in India. $^{4}$

Type of seizure pattern showed maximum number of cases belonged to generalised seizures which is different from Western countries where partial seizure is the commonest variety. ${ }^{1}$

Accurate diagnosis and seizure type is essential for proper management of epilepsy patients and this can be classified as;

\section{International classification of seizures ${ }^{5}$}

\section{Partial seizures}

- $\quad$ Simple partial seizures (consciousness not impaired)

- Complex partial seizures (with impaired consciousness)

- Partial seizures evolving to secondarily generalized seizures.

\section{Generalized seizures}

- Absence seizures (formerly called petit mal)

- Myoclonic seizure

- Clonic seizures

- Tonic seizures

- Tonic clonic seizures (formerly called grand mal)

- Atonic seizures (drop attacks).

The general approach to treatment involves the identification of goals, assessment, development of a care plan, and a follow-up evaluation. During the assessment phase, it is critical to establish an accurate diagnosis of the seizure type and classification. ${ }^{6}$

Over $80 \%$ of epileptic patients can achieve a significant reduction in seizure frequency with one drug alone. The risks of significant adverse effects and drug interaction increase when more than one drug is used. ${ }^{7}$

The AEDs can be grouped according to their main mechanism of action, although many of them have several actions and others have unknown mechanisms of action. The main groups include sodium channel blockers, calcium current inhibitors, gamma-amino butyric acid (GABA) enhancers, glutamate blockers, carbonic anhydrase inhibitors, hormones, and drugs with unknown mechanisms of action. ${ }^{8}$

Drugs acting on various channels summarized below.

With the above mentioned background we conducted a study to evaluate drug utilization pattern in tertiary care hospital.

\section{METHODS}

The design of this study was prospective, cross-sectional, observational drug utilization study. Inclusion/exclusion criteria: All ages, either gender receiving antiepileptic prescription in epilepsy OPD. Site of this study was tertiary care hospital Aurangabad. And the duration of this study was 6 months.

The main objectives of the study was to most commonly prescribed anti-epileptic drug in this study and the commonest drug prescribed for each seizure type.

- Number of patients receiving monotherapy or combination therapy

- The types of seizures encountered in this study and their frequency

- Average number of drugs per encounter

- Percentage of drugs prescribed by generic name.

\section{RESULTS}

The various antiepileptic drugs used in our hospital

- Sodium valproate

- Phenytoin

- Carbamazepine

- Oxcarbazepine

- Topiramate

- Lamotrigene

562 patients from outpatient department were included in prospective observational study of 8 months. The demographic data revealed that number of male and female patients were $53 \%$ and $47 \%$ respectively. Age group included were 1 year to onwards. 13-30 Age groups is most commonly involved.

\section{Classification and etiology of epileptic seizures}

Idiopathic epilepsy is the most common cause of epileptic seizures followed by systemic diseases, head injury, infection, and metabolic derangements.

Generalized tonic-clonic seizures accounted for almost $62 \%$, followed by partial seizures, myoclonic seizures others (traumatic, infectious, systemic disorder, metabolic derangement). 
The classifications of epileptic seizures are summarized in Table 1 AED utilization pattern.

Table 1: AED utilization pattern.

\begin{tabular}{|ll|}
\hline Type of seizures & Percentage \\
\hline $\begin{array}{l}\text { Generalised tonic clonic } \\
\text { seizure }\end{array}$ & $62 \%$ \\
\hline Partial seizures & $18 \%$ \\
\hline Myoclonic & $9 \%$ \\
\hline Absence & $5.5 \%$ \\
\hline Other & $5.5 \%$ \\
\hline
\end{tabular}

Total 786 antiepileptic drugs were prescribed in study duration. Monotherapy was used in 55\% that is in 340 patients followed by duel therapy in $35 \%$ and three drugs were also used for resistant and uncontrolled epilepsy in $4 \%$ of patients.

Table 2: AED use profile.

\begin{tabular}{|ll|}
\hline Drug used & Percentage \\
\hline Sodium valproate & $62 \%$ \\
\hline Phenytoin & $20 \%$ \\
\hline Carbamazepine & $10 \%$ \\
\hline Oxcarbazepine & $4 \%$ \\
\hline Topiramate & $3 \%$ \\
\hline Lamotrigene & $1 \%$ \\
\hline
\end{tabular}

Most common antiepileptic in monotherapy and in combination therapy was sodium valproate followed by phenytoin and carbamazepine the newer drugs were also prescribed for refractory epilepsy. AED use profile is summarized below in Table 2 .

Table 3: Drugs used in GCTS.

\begin{tabular}{|ll|}
\hline $\begin{array}{l}\text { Drugs used in generalised tonic clonic } \\
\text { seizure }\end{array}$ & Percentage \\
\hline Sodium valproate & $60 \%$ \\
\hline Phenytoin & $35 \%$ \\
\hline Topiramate & $5 \%$ \\
\hline
\end{tabular}

Table 4: The second common seizure type was partial followed by myoclonic, absence and others and drugs.

\begin{tabular}{|ll|}
\hline Type of seizures & Drug used \\
\hline Partial & $\begin{array}{l}\text { Carbamazepine, Oxcarbazepine } \\
\text { Sodium valproate, phenytoin }\end{array}$ \\
\hline Myoclonic & Sodium valproate, Topiramate \\
\hline Absence & $\begin{array}{l}\text { Sodium valproate, Topiramate } \\
\text { lamotrigene }\end{array}$ \\
\hline Others & $\begin{array}{l}\text { Sodium valproate, Phenytoin } \\
\text { Carbamazepine, oxcarbazepine }\end{array}$ \\
\hline
\end{tabular}

Generalised tonic clonic seizure type is most frequently encounter seizure type and treated with sodium valproate in $60 \%$ of cases other required alternative drugs like phenytoin, topiramate in combination and as single alternative agent. Drugs used in GCTS summarised below in Table 3.

The second common seizure type was partial followed by myoclonic, absence and others and drugs used in these are summarised in table below in Table 4.

\section{DISCUSSION}

The best way to treat epilepsy is to first identify the cause and the type of epileptic seizures. Most of the patients usually responds to old first line drugs for that epilepsy and the newer drugs can be used in those who do not responds to single or combination of first line antiepileptic's. Monotherapy was prescribed for the majority of GTCS and partial seizures, combination and newer drugs.

In our study, sodium valproate was the first-line drug prescribed in generalized seizures, followed by carbamazepine and phenytoin. Carbamazepine and sodium valproate were the AEDs of choice for the treatment of partial seizures. In this study group, sodium valproate was most commonly prescribed for the treatment of GTCS, absence, myoclonic seizures.

The average drug per prescription was 1.4 drug/person and the Percentage of drugs prescribed by generic name was $93.5 \%$.

Percentage of drugs prescribed from essential drugs list or formulary was $92 \%$ and the prescription pattern was highly influenced by the availability of drugs in hospital pharmacy and economic status of patients. Newer AEDs, used as monotherapy, may be cost-effective for the treatment of patients who have experienced adverse events with older AEDs who have failed to respond to the other drugs, or where such drugs are contraindicated. ${ }^{9}$

The standard AEDs such as carbamazepine, phenytoin and sodium valproate have been shown to have equivalent efficacy in the management of epileptic seizures. A more favourable pharmacokinetic profile is observed in the majority of the newer AEDs in contraposition to the classic agents. Good absorption linear kinetics and low drug-drug interaction potential make these drugs easier to use. $^{10}$

\section{CONCLUSION}

Drug utilization studies have always helped in modifying the prescription guidelines according to the pattern of diseases coming to the healthcare centres. These kinds of studies have an important role in studying and making rational prescription and making drug utilization at most useful to the patients. 
Funding: No funding sources

Conflict of interest: None declared

Ethical approval: The study was approved by the Institutional Ethics Committee

\section{REFERENCES}

1. Dukes MNG. Introduction. In: Drug Utilization Studies: methods and uses. Edited by Dukes MNG. WHO Regional Publications, European Series, No. 1992;45:1-4.

2. Sjoquist F, Birkett D. Drug utilization. In: introduction to drug utilisation research. WHO office of Publications. 2003;76-84.

3. Sathvik BS. Drug utilization review/evaluation. In: a textbook of clinical pharmacy practice. Parthasarathi G, Nyfort-Hansen K, Nahata MC. eds. $1^{\text {st }}$ ed. Orient Longman, India. 2004:362-375.

4. Epilepsy foundation. Available at www.epilepsyfoundation.org. Accessed on 17 March 2014.
5. Ray BK, Bhattacharya S, Kundu TN, Saha SP, Das SK. Epidemiology of epilepsy: Indian perspective. J Indian Med Assoc. 2002;100(5):322-6.

6. Brodie MJ, French JA. Management of epilepsy in adolescents and adults. Lancet. 2000;356:323-8.

7. Herkes GK. Antiepileptics: clinical applications. Aust Prescr. 1994;17:9-12.

8. Antiepileptic drugs: Author: Juan G Ochoa, Selim R Benbadis. Available http://emedicine.medscape.com/article/1187334overview. Accessed on 07 March 2014.

9. Wilby J, Kainth A, Hawkins N, Epstein D. Mc Intosh $\mathrm{H}$, Mc Daid C, et al. Clinical effectiveness, tolerability and cost-effectiveness of newer drugs for epilepsy in adults: a systematic review and economic evaluation. Health Technol Assess. 2005;9(15):1157.

10. Asconape JJ. Some common issues in the use of antiepileptic drugs. Semin Neurol. 2002;22(1): 27-39.

Cite this article as: Morge AS, Kulkarni M. Drug utilization study of antiepileptic drugs in tertiary care hospital. Int J Basic Clin Pharmacol 2016;5:2257-60. 